\title{
Assessment of the body posture of mouth-breathing children and adolescents
}

\author{
Patrícia Blau Margosian Conti, ${ }^{1}$ Eulália Sakano, ${ }^{2}$ Maria Ângela Gonçalves de Oliveira Ribeiro, ${ }^{3}$ \\ Camila Isabel Santos Schivinski, ${ }^{4}$ José Dirceu Ribeiro ${ }^{5}$
}

\begin{abstract}
Objective: To investigate associations between mouth breathing $(\mathrm{MBr})$, nose breathing $(\mathrm{NBr})$ and body posture classification and clinical variables in children and adolescents, by comparing patients with mouth breathing syndrome with a control group of similar age.

Methods: This was an observational, analytical, controlled, cross-sectional study conducted at a university hospital. Children aged 5 years or more were recruited to one of two groups: healthy controls ( $\mathrm{NBr}$ ) or an $\mathrm{MBr}$ group. The $\mathrm{MBr}$ group comprised patients with a diagnosis of mouth breathing syndrome confirmed by clinical examination by a physician plus nasal endoscopy. The control group comprised healthy volunteers of the same age, with $\mathrm{NBr}$ confirmed by medical examination. All participants underwent postural assessment. Data were analyzed using the Mann-Whitney nonparametric test, the chi-square test and Fisher's exact test, to a significance level of $0.05 \%$.

Results: A total of $306 \mathrm{MBr}$ and $124 \mathrm{NBr}$ were enrolled. Mouth breathers were more likely to be male $(p=0.0002)$, have more frequent and more severe nasal obstruction and larger tonsils $(p=0.0001)$ than $\mathrm{NBr}$. Mouth breathers also exhibited higher incidence rates of allergic rhinitis $(p=0.0001)$, of thoracic respiratory pattern $(p=0.0001)$, high-arched palate $(p=0.0001)$ and unfavorable postural classifications $(p=0.0001)$ with relation to the control group. Postural classification scores were directly proportional to nasal obstruction $(p=0.0001)$ and male sex $(\mathrm{p}=0.0008)$.
\end{abstract}

Conclusions: Postural problems were significantly more common among children in the group with mouth breathing syndrome, highlighting the need for early interdisciplinary treatment of this syndrome.

J Pediatr (Rio J). 2011;87(4):357-363: Mouth breathing, child, adenoids, tonsils, rhinitis, prevalence.

\section{Introduction}

If a child's respiratory pattern becomes abnormal for a long period, changing from nasal to oral, physiological features of breathing may be modified. This condition is defined as mouth breathing syndrome (MBS) if it persists for 6 months or longer. Mouth breathing syndrome is common in childhood and the prevalence among schoolage children in Brazil varies from 26.6 to $53.3 \% .^{1-5}$
Many different studies have found evidence of the harm that MBS causes in children and adolescents, including functional abnormalities and involvement of organs and systems.1,3,5,6

It is rare for people to breathe exclusively through the mouth and the majority exhibit mixed breathing. In such cases some air, however little, does pass through the nose

1. Fisioterapeuta. Supervisora, Cursos de Especialização e Aprimoramento em Fisioterapia Pediátrica, Faculdade de Ciências Médicas (FCM), Universidade Estadual de Campinas (UNICAMP), Campinas, SP, Brazil.

2. Doutora. Professora, Responsável, Setor de Rinossinusologia, Centro do Respirador Bucal, Disciplina de Otorrinolaringologia, FCM, UNICAMP, Campinas, SP, Brazil.

3. Doutora. Professora, Coordenadora, Cursos de Especialização e Aprimoramento em Fisioterapia Pediátrica, Serviço de Fisioterapia Pediátrica, UNICAMP, Campinas, SP, Brazil.

4. Doutora. Professora, Disciplina de Fisioterapia em Pediatria, Graduação em Fisioterapia, Universidade do Estado de Santa Catarina (UDESC), Florianópolis, SC, Brazil.

5. Doutor. Professor livre-docente, Departamento de Pediatria. Centro de Investigação em Pediatria, Departamento de Pediatria, FCM, UNICAMP, Campinas, SP, Brazil.

No conflicts of interest declared concerning the publication of this article.

Suggested citation: Conti PB, Sakano E, Ribeiro MA, Schivinski Cl, Ribeiro JD. Assessment of the body posture of mouth-breathing children and adolescents. J Pediatr (Rio J). 2011;87(4):357-63

Manuscript submitted Jan 18 2011, accepted for publication Mar 302011

doi:10.2223/JPED.2102 
and variations in the volume are dependent on circadian rhythms. Mouth breathing syndrome is not a physiological adaptation to problems with breathing through the nose and should be approached as a pathological adaptation. 7,8

The principal etiologic bases of MBS are mechanical obstruction of the upper airways (adenotonsillar hyperplasia, inferior turbinate hypertrophy and nasal septum abnormalities), inflammatory diseases (allergic rhinitis) and congenital malformations with craniofacial deformities. $2,7,9$

In chronic mouth breathing air reaches the lungs via a shorter and easier path. This can lead to changes in respiratory rhythm with deglutition of air, which causes abdominal distension and flaccidity, compromising thoracic expansion and pulmonary ventilation. Changes to muscle strength balance have also been observed, in addition to effects on growth and development, caused by poor respiratory mechanics and function. 2,7,8

Other harmful consequences of MBS include a negative influence on stomatognathic system development, sleep disorders, educational problems, unhealthy nutritional status, reduced quality of life and poor body posture. Children with MBS can exhibit cervical lordosis with protrusion of the mandible and head in an attempt to increase the flow of air through the pharynx ${ }^{9}$ but the relationship has received little attention.

An understanding of the harmful effects of bad posture on children with MBS could guide patient management and reduce the costs involved.

The objective of this study was to investigate associations between mouth breathing $(\mathrm{MBr})$ and nose breathing $(\mathrm{NBr})$ and body posture in children and adolescents, by comparing MBS patients with a control group of similar age.

\section{Methods}

This was an observational, analytical, controlled, crosssectional study of patients from a Mouth Breathing Clinic run by the Otorhinolaryngology Department at the Universidade Estadual de Campinas (UNICAMP) teaching hospital and was conducted between April 2008 and October 2009.

The study was approved by the institution's Ethics Committee under protocol number 114/2008 and the parents or guardians of all participants signed free and informed consent forms.

Children and adolescents aged 5 to 14 years of any ethnicity and both sexes were recruited either to a control group of $\mathrm{NBr}$ children or to a study group of $\mathrm{MBr}$ children. The professional responsible for assessments was blinded to which group each patient belonged.

The $\mathrm{MBr}$ group had their diagnoses of MBS confirmed by otorhinolaryngological examination and nasal endoscopy. Healthy children with similar ages to those in the study group were recruited from a public school and enrolled in the control group.

Exclusion criteria were severe heart disease, prior musculoskeletal injury or any disease that affects the upper or lower extremities. ${ }^{10}$

Patients were taken off the study if they changed their minds about taking part, if they were unable to do the postural assessment or if they did not reply to the questions on the assessment chart. Both groups were assessed by the same teams of physicians and physiotherapists.

The assessment instruments used were a data collection form and the New York State postural assessment method. ${ }^{11}$ This objective method evaluates 13 different body segments according to the following scale: 5.0 for normality; 3.0 for moderate postural problems; and 1.0 for severe postural problems.

Each participant's posture is assessed from the dorsal viewing position (posterior plane), including the head, shoulders, spinal column, hips, feet and arches, and in the lateral plane, including the neck, thorax, shoulders, thoracic spine, trunk and pelvis, lumbosacral spine and abdomen. The final postural assessment score is obtained by summing the points for all items. Scores in the range of 56-65 are defined as normal, from 40-55 as moderate postural problems and scores in the range of 1-39 points are classified as severe postural problems.

Body mass index (BMI) was calculated using the formula weight/height ${ }^{2}\left(\mathrm{~kg} / \mathrm{m}^{2}\right)$ and compared with the Centers for Disease Control's 2000 BMI curves using the following cutoff points: malnutrition ( $\leq$ P3); normal ( $\geq$ P3 $<$ P85); overweight ( $\geq$ P85 < P95); and obesity ( $\geq$ P95).

Patients were classified as having thoracic and/or abdominal respiratory patterns depending on which body segment predominated in terms of inspiratory expansion: possible definitions were thoracic, abdominal or mixed. ${ }^{2,8}$

All nasal endoscopies were conducted by the same otorhinolaryngologist, using a flexible endoscope (Machida ${ }^{\circledR}$, New York, United States) with a diameter of $2.7 \mathrm{~mm}$ to evaluate the size of the tonsils and the nasal turbinates, as described by Modrzynski \& Zawisza, ${ }^{12}$ while the size of tonsils was assessed as described by Brodsky. ${ }^{13}$

Allergic rhinitis was diagnosed and classified as recommended by ARIA $^{14}$ and palate classification was as described by Ricketts. ${ }^{15-17}$

The data thus obtained were analyzed using SPSS version 11.0 with the Mann-Whitney, chi-square and Fisher's exact tests. Values of $p \leq 0.05$ were defined as significant. ${ }^{18-21}$

\section{Results}

The clinic's entire population of 336 children with MBS were invited to take part in the study. Thirty of them refused 
to take part. None of the children who were recruited dropped out early. One hundred and twenty-four $\mathrm{NBr}$ children were recruited for the control group.

There were no statistically significant differences between the two groups in terms of weight, age, height or BMI. There was a statistically significant difference in sex distribution in the $\mathrm{MBr}$ group, with males predominating $(p=0.0002)$.

Tonsil size was statistically larger in the $\mathrm{MBr}$ group $(p=0.0001)$, nasal obstruction was more common in the $\mathrm{MBr}$ group ( $\mathrm{p}=0.0001)$ and the prevalence of allergic rhinitis (AR) was $89.10 \%$ in the $\mathrm{MBr}$ group and just $29.70 \%$ in the $\mathrm{NBr}$ group ( $p=0.0001)$.

The results for thoracic, abdominal and mixed respiratory patterns were as follows: $42.21,20.49$ and $37.30 \%$ in the $\mathrm{MBr}$ group and $18.55,44.35$ and $37.10 \%$ in the $\mathrm{NBr}$ group. There were statistically significant differences between the groups for thoracic and abdominal respiratory patterns $(p=0.0001)$.
The prevalence rates of high-arched palate were 30 and $4.46 \%$ for the $\mathrm{MBr}$ and $\mathrm{NBr}$ groups respectively $(p=0.0001)$.

In the $\mathrm{MBr}$ group, $60.74 \%$ of cases had a normal postural classification, $29.63 \%$ were scored moderate and $9.63 \%$ had severe postural problems. In the $\mathrm{NBr}$ group, $56.20 \%$ had normal posture, $42.98 \%$ had moderate problems and $0.83 \%$ had severe postural abnormalities $(p=0.0001)$.

When evaluated from behind, the segments head, shoulders, feet and arches exhibited statistically significant differences between the $\mathrm{MBr}$ and $\mathrm{NBr}$ groups ( $\mathrm{p} \leq 0.0002$ ). The segments spine and hips did not exhibit statistically significant differences between groups (Table 1 ).

In the lateral plane, the segments thorax, shoulders, spine, trunk and abdomen also exhibited statistically significant differences between the 2 groups ( $p \leq 0.0003$ ) and only the neck posture scores did not differ significantly between groups (Table 1 ).

Table 1 - Distribution of results, in percentages and absolute numbers of children, for postural problems observed in the posterior and lateral planes, broken down by mouth or nose breathing

\begin{tabular}{|c|c|c|c|c|c|c|c|c|}
\hline \multirow[b]{2}{*}{ SA (PP/LP)/BT } & \multicolumn{2}{|c|}{ Severe (\%) } & \multicolumn{2}{|c|}{ Moderate (\%) } & \multicolumn{2}{|c|}{ Normal (\%) } & \multicolumn{2}{|c|}{$\mathbf{p}$} \\
\hline & PP & LP & PP & LP & PP & LP & PP & LP \\
\hline \multicolumn{9}{|l|}{ Head/neck } \\
\hline $\mathrm{MBr}$ & $5(1.87)$ & $11(4.12)$ & 112 (41.95) & $151(56.55)$ & $150(56.18)$ & $105(39.33)$ & $0.0002^{\dagger}$ & $0.260 *$ \\
\hline $\mathrm{NBr}$ & $0(0.00)$ & $2(1.80)$ & $25(22.52)$ & $57(51.35)$ & $86(77.48)$ & $52(46.85)$ & & \\
\hline \multicolumn{9}{|l|}{ Shoulders } \\
\hline $\mathrm{MBr}$ & $11(4.12)$ & $5(1.87)$ & $169(63.30)$ & $90(33.71)$ & $87(32.58)$ & $172(64.42)$ & $0.0004 *$ & $0.0033^{+}$ \\
\hline $\mathrm{NBr}$ & $0(0.00)$ & $0(0.00)$ & $53(47.75)$ & $21(18.92)$ & $58(52.25)$ & $90(81.08)$ & & \\
\hline \multicolumn{9}{|l|}{ Spine } \\
\hline $\mathrm{MBr}$ & $5(1.87)$ & $50(18.3)$ & $94(35.21)$ & $145(54.31)$ & $168(62.92)$ & 72 (26.97) & $0.1952^{+}$ & $0.0308 *$ \\
\hline $\mathrm{NBr}$ & $0(0.00)$ & $15(13.51)$ & $36(32.43)$ & $51(45.95)$ & $75(67.57)$ & $45(40.54)$ & & \\
\hline \multicolumn{9}{|l|}{ Hips/thorax } \\
\hline $\mathrm{MBr}$ & $2(0.75)$ & $6(2.25)$ & $114(42.70)$ & $70(26.22)$ & $151(56.55)$ & $191(71.54)$ & $0.3172^{+}$ & $0.0001^{+}$ \\
\hline $\mathrm{NBr}$ & $0(0.00)$ & $0(0.00)$ & $45(40.54)$ & $10(9.01)$ & $66(59.46)$ & 101 (90.99) & & \\
\hline \multicolumn{9}{|l|}{ Feet/trunk } \\
\hline $\mathrm{MBr}$ & $4(1.50)$ & $10(3.75)$ & $97(36.33)$ & $116(43.45)$ & $166(62.17)$ & $141(52.81)$ & $0.0001^{+}$ & $0.0001 *$ \\
\hline $\mathrm{NBr}$ & $0(0.00)$ & $0(0.00)$ & $16(14.41)$ & $13(11.71)$ & 95 (85.59) & $98(88.29)$ & & \\
\hline \multicolumn{9}{|l|}{ Arches/abdomen } \\
\hline $\mathrm{MBr}$ & $14(5.24)$ & $11(4.12)$ & $105(39.33)$ & $132(49.44)$ & $148(55.43)$ & $124(46.44)$ & $0.0001 *$ & $0.0001 *$ \\
\hline $\mathrm{NBr}$ & $0(0.00)$ & $1(0.90)$ & $15(13.51)$ & $32(28.83)$ & $96(86.49)$ & $78(70.27)$ & & \\
\hline \multicolumn{9}{|l|}{ LS spine } \\
\hline $\mathrm{MBr}$ & & $11(4.12)$ & & $109(40.82)$ & & $147(55.06)$ & & $0.0001 *$ \\
\hline $\mathrm{NBr}$ & & $0(0.00)$ & & $24(21.62)$ & & $87(78.38)$ & & \\
\hline
\end{tabular}

Data shown as absolute numbers of children plus relative frequencies.

$\mathrm{LS}=$ lumbosacral; $\mathrm{LP}=$ lateral plane; $\mathrm{PP}=$ posterior plane; $\mathrm{NBr}=$ nose breathing; $\mathrm{MBr}=$ mouth breathing; $\mathrm{SA}=$ segment assessed; $\mathrm{BT}=$ breathing type (mouth/ nose).

* Chi-square test.

† Fisher's exact test. 
There were no statistically significant differences between the three postural classifications in terms of the variables weight, height or BMI. These comparisons between severe, moderate and normal postural groups were made using means and percentiles ( $p>0.17$ ).

There were no differences between different postural groups in the $\mathrm{MBr}$ subset in terms of the frequency of palate abnormalities ( $p>0.05$ ).

Taking the entire sample of $\mathrm{MBr}$ and $\mathrm{NBr}$ children, the prevalence rates of AR in the different postural categories were $88.89 \%$ in the severe group, $68.75 \%$ in the moderate group and $59.43 \%$ of those with normal posture $(p=0.11)$. In contrast, there were no statistically significant differences when the $\mathrm{MBr}$ and $\mathrm{NBr}$ groups were taken in isolation ( $p>0.05$ ).

The proportions in each postural severity category differed by both sex and the presence of nasal obstruction for both groups. A greater proportion of the entire subset of boys had severe postural problems than in the subset of girls $(p=0.0008)$. The frequency of nasal obstruction differed significantly according to postural classification $(p=0.0001)$. Postural categories did not affect academic performance in either group ( $p>0.05)$.

Table 2 shows the distribution of odds ratios produced by univariate logistic regression for the $\mathrm{MBr}$ group and also the multivariate logistic regression results for the $\mathrm{MBr}$ group. The distribution of the probability of MBS according to sex, respiratory pattern and postural classification is shown in Table 3.

\section{Discussion}

This study has confirmed an association between MBS and body posture in children and adolescents. We could not find any studies in the literature that have previously correlated breathing type (mouth or nose) with different degrees of body posture problems.

There was a greater prevalence of males in the $\mathrm{MBr}$ group. This has been reported by many authors, ${ }^{8,2}$ although others have failed to find differences in prevalence between the sexes. 3,4 This greater prevalence of MBS among males may be the result of a narrower lower respiratory tract and an increased prevalence of allergic rhinitis among boys. ${ }^{22}$

We did not find a correlation between the postural problems in $\mathrm{MBr}$ or $\mathrm{NBr}$ and their weight, height or BMI.

De Menezes et al. ${ }^{3}$ assessed the nutritional status of children with MBS in order to establish a relationship between respiratory pattern and obesity. They found that MBS provokes eating disorders and masticatory problems and that these can lead to obesity.

Irrespective of the cause, chronic nasal obstruction in infancy leads to supplementary $\mathrm{MBr}$. Mocellin et al. ${ }^{22}$

Table 2 - Results of univariate logistic regression for likelihood of being in $\mathrm{MBr}$ group and results of multivariate logistic regression* for the same group

\begin{tabular}{|c|c|c|c|c|c|}
\hline Parameters & $\mathbf{n}$ & $\begin{array}{l}\text { Parameter } \\
\text { estimated }\end{array}$ & $\mathbf{p}$ & Odds ratio & $95 \% \mathrm{CI}$ \\
\hline Intercept & & & 0.0002 & & \\
\hline \multicolumn{6}{|l|}{ Sex } \\
\hline Male vs. female & 430 & 0.7959 & 0.0003 vs. 0.356 & 2.216 vs. 1.688 & $\begin{array}{c}1.447-3.394 \\
\text { vs. } 1.036-2.750\end{array}$ \\
\hline \multicolumn{6}{|l|}{ Rhinitis } \\
\hline Yes vs. no & 257 & 2.9627 & 0.0001 & 19.350 & $10.000-37.443$ \\
\hline \multicolumn{6}{|l|}{ Respiratory pattern } \\
\hline Thoracic vs. abdominal & 368 & 1.5945 & 0.0001 vs. 0.0001 & 4.926 vs. 4.998 & $\begin{array}{c}2.724-8.908 \\
\text { vs. } 2.651-9.423\end{array}$ \\
\hline Mixed vs. abdominal & & 0.7775 & 0.0035 vs. 0.0125 & 2.176 vs. 2.047 & $\begin{array}{c}1.291-3.667 \\
\text { vs. } 1.167-3.593\end{array}$ \\
\hline \multicolumn{6}{|l|}{ Postural classification } \\
\hline Severe vs. normal & 391 & 3.0956 & 0.0027 vs. 0.0021 & 22.100 vs. 24.990 & $\begin{array}{c}2.922-167.146 \text { vs. } \\
3.217-194.127\end{array}$ \\
\hline Moderate vs. normal & & 0.9861 & 0.0001 vs. 0.0001 & 2.681 vs. 2.911 & $\begin{array}{c}1.711-4.201 \text { vs. } \\
1.775-4.774\end{array}$ \\
\hline
\end{tabular}

$95 \% \mathrm{Cl}=95 \%$ confidence interval.

${ }^{*}$ For multivariate logistic regression, $\mathrm{C}=0.727$ (accuracy of the model). 
Table 3 - Distribution of probability of Mouth Breathing Syndrome depending on sex, respiratory pattern and postural classification

\begin{tabular}{|c|c|c|c|c|}
\hline \multirow[b]{2}{*}{ Sex } & \multirow[b]{2}{*}{ Respiratory pattern } & \multirow[b]{2}{*}{ Postural classification } & \\
\hline & & & $\mathrm{MBr}$ & $\mathrm{NBr}$ \\
\hline Female & Abdominal & Normal & 0.2655 & 0.7345 \\
\hline Male & Abdominal & Normal & 0.3789 & 0.6211 \\
\hline Female & Mixed & Normal & 0.4253 & 0.5747 \\
\hline Female & Abdominal & Moderate & 0.5127 & 0.4873 \\
\hline Male & Mixed & Normal & 0.5553 & 0.4447 \\
\hline Male & Abdominal & Moderate & 0.6397 & 0.3603 \\
\hline Female & Thoracic & Normal & 0.6437 & 0.3563 \\
\hline Female & Mixed & Moderate & 0.6830 & 0.3170 \\
\hline Male & Thoracic & Normal & 0.7530 & 0.2470 \\
\hline Male & Mixed & Moderate & 0.7843 & 0.2157 \\
\hline Female & Thoracic & Moderate & 0.8402 & 0.1598 \\
\hline Male & Thoracic & Moderate & 0.8987 & 0.1013 \\
\hline Female & Abdominal & Severe & 0.9003 & 0.0997 \\
\hline Male & Abdominal & Severe & 0.9384 & 0.0616 \\
\hline Female & Mixed & Severe & 0.9487 & 0.0513 \\
\hline Male & Mixed & Severe & 0.9690 & 0.0310 \\
\hline Female & Thoracic & Severe & 0.9783 & 0.0217 \\
\hline Male & Thoracic & Severe & 0.9870 & 0.0130 \\
\hline
\end{tabular}

$\mathrm{NBr}=$ nose breathing; $\mathrm{MBr}=$ mouth breathing.

investigated the principal causes of chronic nasal obstruction in infancy and found that $16.67 \%$ had adenoid hypertrophy in isolation and none had only hypertrophic tonsils. Nevertheless, $3.33 \%$ had hypertrophy of both structures and $36.67 \%$ had a combination of adenoid hypertrophy, tonsil hypertrophy and inferior turbinate hypertrophy. ${ }^{22}$

Abreu et al. ${ }^{5}$ investigated children with MBS and found that $79.2 \%$ had hypertrophic adenoids and $12.6 \%$ had hypertrophic tonsils. These results are similar to the figures for our population, in terms of the elevated incidence of enlarged tonsils and adenoids. ${ }^{5}$

In our study, patients had significantly larger tonsils and adenoids than the controls. However, the size of adenoids may not be the only cause of MBS. Even after surgical removal or medication, some patients continue to breathe through their mouths because of other intercurrent factors.

Allergic rhinitis has been described as one of the primary factors associated with MBS in childhood. ${ }^{2}$ We observed a significantly greater prevalence of this dysfunction in the group with MBS when compared with the NBr group, irrespective of their postural categories.
The combination of allergic rhinitis and MBS can cause hypertrophy of the nasal turbinates, abnormalities of the dental arch and of craniofacial growth and problems with speech, mastication, body posture, academic achievement and sleeping. ${ }^{2}$

Many authors have found elevated prevalence of high-arched palate among children with nasal obstruction compared with children without nasal obstruction.7,8

Motonaga et al. ${ }^{23}$ observed high-arched palate in $87.50 \%$, whereas in our study we found that $30 \%$ of $\mathrm{MBr}$ and $4.46 \%$ of the $\mathrm{NBr}$ had a high-arched palate.

Our children with MBS had a $42.21 \%$ prevalence of the thoracic respiratory pattern. The abdominal pattern was most common among $\mathrm{NBr}$ children (44.35\%). These results indicate that thoracoabdominal mobility differs between the groups. However, a study that assessed thoracoabdominal motion in $\mathrm{MBr}$ and $\mathrm{NBr}$ children using respiratory plethysmography did not find results compatible with ours. ${ }^{24}$ They found that airway obstruction leads to respiratory overload, increasing the phase angle. However, they observed that thoracoabdominal motion was almost 
synchronous for the $\mathrm{MBr}$ and $\mathrm{NBr}$ children and that both groups had small phase angles. These authors questioned whether airway obstruction is truly predictive of altered thoracoabdominal synchronisation. 24

A study that investigated the pulmonary function and habits of mouth breathers using respiratory biofeedback associated with a quiet breathing pattern observed that $\mathrm{MBr}$ children had an irregular respiratory pattern with predominance of thoracic breathing and low amplitude abdominal motion. ${ }^{25}$ The same was observed in our study.

Analysis of the postural assessment results for the posterior plane indicated a statistically significant predominance of problems in certain body segments. These results are in agreement with other researchers ${ }^{25}$ who have demonstrated prevalence rates of $100 \%$ for anterior displacement of the head, $82 \%$ for anterior displacement of the shoulder, $94 \%$ for subtalar joint abnormalities, $71 \%$ for increased lumbar curvature and $10 \%$ for abdominal protrusion. Notwithstanding, the elevated prevalence of cervical flexion was not observed in our sample of $\mathrm{MBr}$.

A 2008 study using the Postural Analysis software (SAPO ${ }^{\circledR}$, Universidade de São Paulo, São Paulo, Brazil) to evaluate the posture of $\mathrm{MBr}$ and $\mathrm{NBr}$ children aged 5 to 12 years ${ }^{26}$ found significant increases in $\mathrm{MBr}$ with relation to $\mathrm{NBr}$ in the angle of cervical lordosis and of thoracic kyphosis. That result corroborates our study, which also detected a significant prevalence of neck, spine and trunk disorders in the lateral plane assessments of MBS children. The angle of lumbar lordosis was significantly smaller in $\mathrm{MBr}$, indicating lumbosacral spine problems. ${ }^{26}$

In the $\mathrm{MBr}$ we found an elevated prevalence of head and shoulders protrusion and of inclination of the head. This shoulder misalignment can be caused by a spine that is deforming into the shape of an S or a C, as observed in $30.5 \%$ of the $\mathrm{MBr}$. These findings were also described by Corrêa \& Bérzin ${ }^{27}$ in 2007 when they conducted a postural assessment of schoolchildren by observational analysis, confirmed by electromyography and computerized image analysis.

We observed thoracic abnormalities such as thoracic retraction, inclination of the trunk and thoracic hyperkyphosis in $\mathrm{MBr}$ and other authors have also done so. 4

Studies undertaken to date indicate that $\mathrm{MBr}$ can cause many respiratory and postural problems. The complexity of the problems that affect patients with this dysfunction mean that multidisciplinary intervention is needed.

The postural assessment method that we employed is a rapid procedure that is noninvasive, low-cost and easily administered in clinical practice and which provides results that correlate with studies that have used clinical and computerized methods. ${ }^{26-29}$ Nevertheless, the importance of, and need for, controlled longitudinal studies in order to determine the specific characteristics of the postural disorders involved cannot be ignored.

Our study suffers from certain limitations, one of which is the New York State postural assessment method which, despite being practical and easy-to-administer, may not be as sensitive as is ideal for identifying discrete abnormalities, since it is observer-dependent and uses only two planes. Further limitations are the fact that the study does not allow for temporal associations, suffers from a risk of selection bias and is only able to identify associations and not causality.

Our data can be used to construct a scale of probability on the basis of the variables studied (Table 3), showing that respiratory type (mouth or nose) is associated with postural classification. Mouth breathing and moderate and severe postural categories confer worse clinical status, which underscores the need to start interdisciplinary treatment of this syndrome as early as possible.

\section{Acknowledgements}

The authors are grateful to the members of the Otorhinolaryngology Department at the UNICAMP Medical Sciences Faculty, to the Statistics Service at the UNICAMP Medical Sciences Faculty and to the physiotherapists Mariana Simões Ferreira and Fabíola Meister Pereira for help with data collection and patient care.

\section{References}

1. Aragão W. Respirador bucal. J Pediatr (Rio J). 1988;64:349-52.

2. Barros JR, Becker HM, Pinto JA. Evaluation of atopy among mouthbreathing pediatric patients referred for treatment to a tertiary care center. J Pediatr (Rio J). 2006;82:458-64.

3. De Menezes VA, Leal RB, Pessoa RS, Pontes RM. Prevalence and factors related to mouth breathing in school children at the Santo Amaro project-Recife, 2005. Braz J Otorhinolaryngol. 2006;72:394-9.

4. Abreu RR, Rocha RL, Lamounier JA, Guerra AF. Etiology, clinical manifestations and concurrent findings in mouth-breathing children. J Pediatr (Rio J). 2008;84:529-35.

5. Abreu RR, Rocha RL, Lamounier JA, Guerra AF. Prevalence of mouth breathing among children. J Pediatr (Rio J). 2008;84:467-70

6. de Freitas FCN, Bastos EP, Primo LS, de Freitas VL. Evaluation of the palate dimensions of patientes with perenial allergic rhinitis. Int J Paediatr Dent. 2001;11:365-71.

7. Di Francesco RC, Passerotii G, Paulucci B, Miniti A. Mouth breathing in children: different repercussions according to the diagnosis. Rev Bras Otorrinolaringol. 2004;70:665-70.

8. Di Francesco RC, Junqueira PA, Frizzarini R, Zerati FE. Weight and height development in children after adenotonsillectomy. Rev Bras Otorrinolaringol. 2003;69:193-6.

9. Neiva PD, Kirkwood RN. Measurement of neck range of motion among mouth-breathing children. Rev Bras Fisioter. 2007; 11:355-60.

10. Hussey J, Gormley J, Leen G, Greally P. Peripheral muscle strength in young males with cystic fibrosis. J Cyst Fibros. 2002;1:116-21.

11. Division of Health, Physical Education and Recreation, New York State Education Department. The New York physical fitness test for Boys and Girls Grades 4-12: a manual for teachers of physical education. Albany, New York; 1958. 
12. Modrzynski M, Zawisza E. An analysis of the incidence of adenoid hypertrophy in allergic children. Int J Pediatr Otorhinolaryngol. 2007;71:713-9.

13. Brodsky L. Tonsillitis, tonsillectomy and adenoidectomy. In: Bailey BJ, editor. Head and Neck Surgery-Otolaryngology. Philadelphia: JB Lippincott; 1993. p. 833-47.

14. Allergic Rhinitis and its Impact on Asthma. 2007. http://www. ariabrasil.med.br/guia.asp. Access: 05/07/07.

15. Ricketts RM. A foundation for cephalometric communication. Am J Orthod. 1960;46:330-57.

16. Ricketts RM. Cephalometric synthesis. Am J Orthod. 1960;46:647-73.

17. Ricketts RM. Respiratory obstruction syndrome. Am J Orthod. 1968;54:495-507.

18. Conover WJ. Practical Nonparametric Statistics. New York: John Wiley \& Sons; 1971.

19. Fleiss JL. Statistical Methods for Rates and Proportions 2. ed. New York: John Wiley \& Sons; 1981.

20. Hosmer DW, Lemeshow S. Applied Logistic Regression. New York: John Wiley \& Sons; 1989.

21. The SAS System for Windows (Statistical Analysis System), versão 9.1.3. Cary, NC, USA: SAS Institute Inc; 2002-2003.

22. Mocellin M, Fugmann EA, Gavazzoni FB, Ataide AL, Ouriques FL, Júnior $\mathrm{FH}$. Estudo cefalométrico-radiográfico e otorrinolaringológico correlacionando o grau de obstrução nasal e o padrão de crescimento facial em pacientes não tratados ortodonticamente. Rev Bras Otorrinolaringol. 2000;66:1-6

23. Motonaga SM, Berte LC, Anselmo-Lima WT. Respiração Bucal: causas e alterações no sistema estomatognático. Rev Bras Otorrinolaringol. 2000;66:373-9.
24. Brant TC, Parreira VF, Mancini MC, Becker HM, Reis AF, Britto RR. Breathing pattern and thoracoabdominal motion in mouthbreathing children. Rev Bras Fisioter. 2008;12:495-501.

25. Barbiero EF, Vanderlei LC, Nascimento PC, Costa MM, Scalabrini Neto $A$. Influence of respiratory biofeedback associated with a quiet breathing pattern on the pulmonary function and habits of functional mouth breathers. Rev Bras Fisioter. 2007;11:347-54.

26. Yi LC, Jardim JR, Inoue DP, Pignatari SS. The relationship between excursion of the diaphragm and curvatures of the spinal column in mouth breathing children. J Pediatr (Rio J). 2008;84:171-7.

27. Corrêa EC, Bérzin F. Efficacy of physical therapy on cervical muscle activity and on body posture in school-age mouth breathing children. Int J Pediatr Otorhinolaryngol. 2007;71:1527-35.

28. Falcão DA, Grinfeld S, Grinfeld A, Melo MV. Oral breathers clinically diagnosed and by autodiagnosed body posture consequences. Int J Dent. 2003;10:250-6.

29. Ribeiro F, Bianconi CC, Mesquita MC, Assencio-Ferreira VJ. Mouth breathing: maloclusion and oral habits. CEFAC. 2002;4:187-90.

Correspondence:

Patrícia Blau Margosian Conti

Alameda Niagara, 262 - Grape Village

CEP 13280-000 - Vinhedo, SP - Brazil

Tel.: +55 (19) 3836.2751, +55 (19) 8119.8954

E-mail: patriciablau@gmail.com 